\title{
Effectiveness of psycho-education on knowledge regarding schizophrenia and caregivers' burden among caregivers of patients with schizophrenia - a randomized controlled trial
}

\author{
SUNANDA GOVINDER THIMMAJJA ${ }^{1, A-F}$, EILEAN VICTORIA LAZARUS RATHINASAMY2, A, c-E \\ ORCID ID: 0000-0002-9224-2212 \\ ${ }^{1}$ Department of Psychiatric Nursing, Dharwad Institute of Mental Health and Neurosciences, Dharwad, India \\ ${ }^{2}$ Department of Adult and Critical Care, College of Nursing, Sultan Qaboos University, Muscat, Oman
}

A - Study Design, B - Data Collection, C - Statistical Analysis, D - Data Interpretation, E - Manuscript Preparation, F - Literature

Search, G - Funds Collection

Summary Background. Schizophrenia is one of the commonly occurring disorders, often causing a high degree of disability to the patients, as well as being stressful to the caregivers.

Objectives. To find the efficacy of psycho-education on knowledge regarding schizophrenia among caregivers and reducing their level of burden.

Material and methods. A randomized controlled trial was used to assess the effectiveness of psycho-education among caregivers of patients with schizophrenia. This study was conducted at a selected state government mental hospital in Karnataka, India. 350 caregivers were randomly assigned to study $(n=175)$ and control groups $(n=175)$. Both the group subjects were initially assessed for knowledge and burden. The study group caregivers participated in one or two psycho-education sessions with routine nursing care. Control group subjects received routine care in the hospital. Post-intervention assessment was done at the end of one-month and three-month intervals.

Results. At pre-test, the study group caregivers' mean knowledge scores were mean $=22.93, S D=17.03$, which was improved to mean $=85.90, \mathrm{SD}=9.51$ at the one-month follow-up and mean $=97.94, \mathrm{SD}=4.41$ at the three-month follow-up. This improvement was statistically significant at a 0.01 level when compared to control group caregivers. The study group caregivers' mean burden scores that were initially recorded at pre-test mean $=82.37, S D=10.40$ reduced to mean $=49.13, S D=8.28$ at the one-month follow-up and mean $=40.86, S D=6.27$ at the three-month follow-up. This improvement was statistically significant at a 0.01 level when compared to control group caregivers.

Conclusions. The study group caregivers showed an improvement in knowledge gain and a reduction in care burden. The present study findings provided evidence for the role of psycho-education intervention in reducing care burden among caregivers of patients with schizophrenia and was also found effective in caring for their relatives with appropriate knowledge.

Key words: schizophrenia, caregivers, education.

Govinder Thimmajja S, Lazarus Rathinasamy EV. Effectiveness of psycho-education on knowledge regarding schizophrenia and caregivers' burden among caregivers of patients with schizophrenia - a randomized controlled trial. Fam Med Prim Care Rev 2019; 21(2): 104-111, doi: https://doi.org/10.5114/fmpcr.2019.84552.

\section{Background}

Mental illnesses are a global public health concern. Schizophrenia is one of the top 15 leading causes of disability worldwide [1]. Estimates of the international prevalence of schizophrenia among non-institutionalized persons is $0.33 \%$ to $0.75 \%[2,3]$.

The burden of care emerged after the closure of mental hospitals when patients were followed-up outside of the hospital settings [4], and the family members assumed responsibility for these patients, thereby becoming the primary caregivers at home [5].

Caregiver burden has two dimensions - subjective and objective. While the subjective component deals with the extent to which the burden is felt by the relatives, the objective burden relates to the ill effects on the household, such as financial difficulty, effects on health, children and disruption in regular family routine due to the patient's abnormal behavior [6]

The media referred to the findings of the report as follows: "India needs to talk about mental illnesses. Every sixth Indian needs mental health help. $8 \%$ of people in Karnataka have mental illnesses. Mental problems are more in the $30-49$ age groups or over 60. Low income is linked to the occurrence of mental disorders, and urban areas are most affected. The overall weighted prevalence for any mental morbidity was $13.7 \%$ life-time and $10.6 \%$ current mental morbidity [7].

Indians suffer from severe mental disorders and common mental disorders. The burden of these disorders is likely to increase to $15 \%$ by 2020 [8].

While a majority of the population lives in rural areas, 80$-90 \%$ of the mental disorders among them were not diagnosed and left untreated due to lack of knowledge and a negative attitude towards mental illness. A stigma and negative attitude towards people with mental illness has been observed among the general population [9].

In India, the annual incidence rates of schizophrenia obtained were 4.4 and 3.8 per 10,000 for rural and urban areas, respectively [10]. More than $70 \%$ of mentally-challenged patients live within the family, and the family is the $24 / 7$ care provider. So, unless the family base is strengthened, the care and rights of mentally ill patients are likely to be compromised irrespective of the various national programs introduced by the government of India. 
Among the many mental illnesses, schizophrenia is a chronic disease that results in a serious form of disability and concerns not only the patients themselves, but also their family members who assume their care [11]. The burden of those providing care to patients with chronic diseases is a global problem. Caring for such patients requires continuous energy, knowledge, empathy and economic power, which all influence daily living to a large extent. While attempting to establish a balance between their jobs, families and their patient care, usually caregivers will neglect their own physical and mental health [11].

The stigma attached to the mental illness, especially schizophrenia, often inhibits the family's willingness to talk about their thoughts and feelings, and the biological factors of the illness interfere with treatment [12].

Family caregivers with a lower education level and increased family hardiness and those with a higher education level had significantly enhanced family functioning. A sense of coherence was significantly correlated with family hardiness [13].

The families who perceived a higher level of caregiver burden were those who lived in a family having poorer functioning, worse health status and less satisfaction of social support [13].

Treatment of schizophrenia is focused primarily on the management of symptoms with drugs. Rehabilitation and psychosocial interventions are frequently neglected and rarely available. Among psychological interventions, psycho-education is one type of intervention that is used to treat patients with schizophrenia, as well as caregivers of patients with schizophrenia.

Nurses and mental health professionals need to collaborate with patients and families to educate and assist them in understanding and coping effectively with mental illnesses. Families often look to nurses for empathy and answers in dealing with these issues. The study showed that 487 family members believed that the factual information about illness, socialization, building support in the family and increased understanding and awareness of the biological basis of mental illness reduced the stigma attached to mental illness. A brief psycho-educational intervention for relatives is effective in improving relatives' knowledge about schizophrenia and reducing re-hospitalization [14].

Caregivers in the intervention group showed significant improvement in knowledge, a reduction in burden while assisting in daily living (severity) and a reduced defaulter rate in patients' follow-up [15].

Many studies have shown that psycho-education interventions may improve patients' and caregivers' outcomes, but the quality of included studies are poor, and it is difficult to draw firm conclusions as to the effectiveness of such interventions on patients' and primary caregivers' outcomes, hence the present study intended to evaluate the efficacy of psycho-education on knowledge regarding schizophrenia and caregiver burden among caregivers of patients with schizophrenia.

The present study has been taken up against the above background, with a purpose to measure the effectiveness of psycho-education on caregivers' knowledge and burden. We hypothesized that subjects in the study group will experience a greater improvement in knowledge regarding schizophrenia and a reduction in caregiver burden compared to control group subjects during follow-up assessments. Therefore, the aim of the present study is to investigate the effectiveness of psycho-education on knowledge regarding schizophrenia and the level caregiver burden among caregivers of patients with schizophrenia.

\section{Objectives}

The aim of the study is to examine the effectiveness of psycho-education on improving knowledge regarding schizophrenia and reducing caregiver burden among caregivers of patients with schizophrenia.

\section{Material and methods}

\section{Design}

The present study used an experimental pre-post control group design with a three-month follow-up.

\section{Participants}

The participants comprised 350 caregivers of patients with schizophrenia who were admitted at a selected state government psychiatric hospital in Karnataka, India. The subjects were selected from the in-patient department of the psychiatric hospital. The participants were randomly assigned to either of the study or control groups via a computer-generated random sequence of numbers. The inclusive criteria for selection of subjects were: the caregivers should be between 15-54 years of age and must be residing with the patients for about six months, and the schizophrenia patients were diagnosed by a psychiatrist based on ICD-10 criteria.

\section{Study instruments}

Section A includes socio-demographic details of the participants, such as age, gender, relationship with patient, residence, type of family, education, occupation, income, duration of respondent's relative suffering from schizophrenia and source of information.

Section B included a questionnaire regarding knowledge on schizophrenia under two areas: 1) General information of schizophrenia containing 7 items focused on introduction, causes, signs and symptoms and course of schizophrenia; and 2) Treatment and management of schizophrenia containing 18 items focused on pharmacological treatment, psychosocial management and nursing management. The maximum score is 25, with 1 mark for each correct answer and 0 marks for each wrong answer. Scores between 0-9 $(<35 \%)$ indicate inadequate knowledge, 10-17 (<65\%) moderate knowledge, and 18-25 (>65\%) adequate knowledge. Content validity was checked by a panel of 12 subject experts. Reliability assessment was done using the test-retest method. The reliability coefficient for the structured knowledge questionnaire was 0.89 [16].

Section C included the Burden Assessment Schedule (BAS) [17], which is a standardized tool used in the Indian context comprising 20 items representing 5 factors or concerns which reflect the caregiver's main feelings about their care-giving role. The 5 factors are: 1) Impact on well-being; 2) Impact on marital relationships; 3) Appreciation for caring; 4) Impact on relations with others; 5) Perceived severity of the disease. The BAS used a three-point Likert scale to assess the caregiver's burden in terms of 'not at all', 'to some extent' and 'very much'. The highest score is 60 . The scores are divided into three levels to perceive the level of caregiver burden, ranging from low to high. Scores between 0-20 denotes low burden, 21-40 denotes average burden, and 41-60 denotes high level. Tools were translated from English to Kannada language by Kannada language experts and retranslated back to English by English language experts.

\section{Intervention}

Psycho-education intervention was developed based on "A manual on family intervention for the mental health professional" $[18,19]$. This was validated by a panel of subject experts. It involves two sessions, each session lasting for 60 to $90 \mathrm{~min}-$ utes. The topics included in psycho-education were - general information on schizophrenia, causes, signs and symptoms, pharmacological management, psycho-social management, nursing management and family roles and responsibilities in management of patients with schizophrenia. It also focused on manage- 


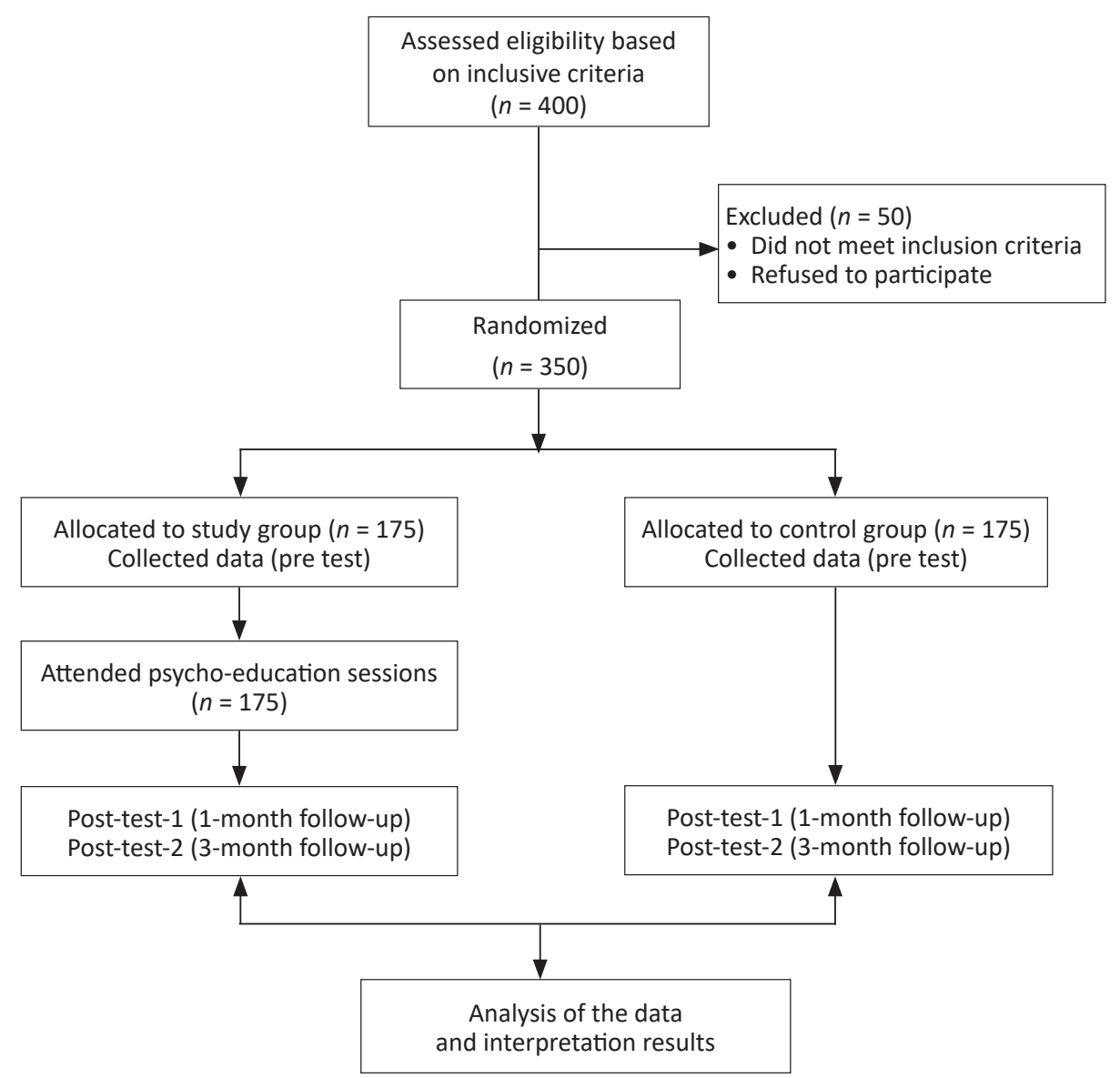

Figure 1. Flow chart of the study

ment of stress and the burnout of caregivers of patients with schizophrenia. Psycho-education was translated into the local language and implemented to the study group by a lecturecum-discussion method, one-to-one or in a group in one session or two sessions with flex charts, a laptop-assisted power point presentation and distributed information brochure.

\section{Data collection}

Study subjects were selected based on inclusive criteria from the in-patient department of a state government psychiatric hospital in Karnataka, India. Data was collected from December 2013 to 2015. Initially, the investigator (first author) approached each participant and assessed them for socio-demographic details, knowledge regarding schizophrenia and burden level using the above tools. Each participant took 30 minutes to complete the questionnaires. Later, the investigator randomly assigned subjects to experimental and control groups using computer-generated random sequence numbers. The experimental group subjects participated in a psycho-education program. The first author provided intervention using a group approach and lecture-cum-discussion method. Psycho-education was imparted using flex charts and a laptop-assisted power point presentation. At the end of the intervention, each caregiver was provided with an information booklet. The control group subjects received only routine care in the hospital. A post-test was conducted at the end of a one-month and two-month period. Caregivers in the control group received information booklets after completion of follow-up assessments (Figure 1).

\section{Ethical consideration}

The study was approved by the institutional ethics committee, and permission was obtained from the hospital authorities.
Participants were explained the purpose of the study, nature of involvement and number of follow-ups, both in oral and written form. The researcher obtained written informed consent before proceeding with the study. The respondents were assured anonymity and confidentiality of the information provided by them.

\section{Data analysis}

Descriptive and inferential statistics were used to analyze the data, and the results were narrated in the form of tables.

\section{Results}

\section{Findings related to socio-demographic characteristics}

Distribution of study subjects based socio-demographic characteristics, majority were belonged to $25-34$ years of age group. A majority of $n=115$ (65.71\%) and $n=112(64 \%)$ respondents were female in the study and control groups, respectively. The majority of the [study $=77(44 \%)$ and control $=70(40 \%)$ ] respondents had a parental relationship with the patient. The majority of the [study $=98(56 \%)$ and control $=96(54.86 \%)$ ] respondents resided in rural areas. $61.7 \%$ of the study group and $52.6 \%$ of the control group subjects belonged to a joint family. $42.86 \%$ of the study group subjects and $31.43 \%$ of the control group subjects studied up to $10+2 /$ Diploma education*. $31.43 \%$ and $36 \%$ of the study and control group subjects respectively pursued farming. The majority of respondents [study $=40$

\footnotetext{
* In our country's education system $10+2$ means $12^{\text {th }}$ class level of education and diploma education means some of the courses are offered after $10^{\text {th }}$ class. So, $10+2$ and diploma education level posses somewhat same level of educational status.
} 


\begin{tabular}{|c|c|c|c|c|c|c|}
\hline Demographic characteristics & $\begin{array}{l}\text { Study group } \\
n=175\end{array}$ & $\%$ & $\begin{array}{l}\text { Control group } \\
n=175\end{array}$ & $\%$ & Total & $\%$ \\
\hline $\begin{array}{l}\text { Age groups in years } \\
15-24 \\
25-34 \\
35-44 \\
45-54 \\
\end{array}$ & \begin{tabular}{|l}
22 \\
68 \\
64 \\
21 \\
\end{tabular} & $\begin{array}{l}12.57 \\
38.86 \\
36.57 \\
12.00 \\
\end{array}$ & $\begin{array}{l}17 \\
47 \\
80 \\
31 \\
\end{array}$ & \begin{tabular}{|l|}
9.71 \\
26.86 \\
45.71 \\
17.71 \\
\end{tabular} & $\begin{array}{l}39 \\
115 \\
144 \\
52 \\
\end{array}$ & $\begin{array}{l}11.14 \\
32.86 \\
41.14 \\
14.86 \\
\end{array}$ \\
\hline $\begin{array}{l}\text { Gender } \\
\text { Male } \\
\text { Female }\end{array}$ & \begin{tabular}{|l|}
60 \\
115 \\
\end{tabular} & $\begin{array}{l}34.29 \\
65.71 \\
\end{array}$ & \begin{tabular}{|l|}
63 \\
112 \\
\end{tabular} & \begin{tabular}{|l|}
36.00 \\
64.00 \\
\end{tabular} & $\begin{array}{l}123 \\
227\end{array}$ & $\begin{array}{l}35.14 \\
64.86 \\
\end{array}$ \\
\hline $\begin{array}{l}\text { Relationship with patient } \\
\text { Spouse } \\
\text { Parent } \\
\text { Siblings } \\
\text { Children } \\
\text { Others }\end{array}$ & $\begin{array}{l}34 \\
77 \\
36 \\
11 \\
17 \\
\end{array}$ & $\begin{array}{l}19.43 \\
44.00 \\
20.57 \\
6.29 \\
9.71 \\
\end{array}$ & $\begin{array}{l}39 \\
70 \\
48 \\
0 \\
18\end{array}$ & $\begin{array}{l}22.29 \\
40.00 \\
27.43 \\
0.00 \\
10.29 \\
\end{array}$ & $\begin{array}{l}73 \\
147 \\
84 \\
11 \\
35 \\
\end{array}$ & $\begin{array}{l}20.86 \\
42.00 \\
24.00 \\
3.14 \\
10.00 \\
\end{array}$ \\
\hline $\begin{array}{l}\text { Place of residence } \\
\text { Urban } \\
\text { Rural }\end{array}$ & $\begin{array}{l}77 \\
98\end{array}$ & $\begin{array}{l}44.00 \\
56.00\end{array}$ & $\begin{array}{l}96 \\
79\end{array}$ & $\begin{array}{l}54.86 \\
45.14\end{array}$ & $\begin{array}{l}173 \\
177\end{array}$ & $\begin{array}{l}49.43 \\
50.57\end{array}$ \\
\hline $\begin{array}{l}\text { Family type } \\
\text { Nuclear } \\
\text { Joint }\end{array}$ & \begin{tabular}{|l|}
67 \\
108 \\
\end{tabular} & $\begin{array}{l}38.29 \\
61.71 \\
\end{array}$ & $\begin{array}{l}83 \\
92 \\
\end{array}$ & $\begin{array}{l}47.43 \\
52.57\end{array}$ & $\begin{array}{l}150 \\
200\end{array}$ & $\begin{array}{l}42.86 \\
57.14 \\
\end{array}$ \\
\hline $\begin{array}{l}\text { Education level } \\
\text { Professional } \\
\text { Graduate/postgraduate } \\
10+2 \text { and diploma } \\
\text { Primary and higher } \\
\text { No formal education }\end{array}$ & $\begin{array}{l}19 \\
27 \\
75 \\
31 \\
23\end{array}$ & $\begin{array}{l}10.86 \\
15.43 \\
42.86 \\
17.71 \\
13.14 \\
\end{array}$ & $\begin{array}{l}26 \\
12 \\
55 \\
34 \\
48\end{array}$ & $\begin{array}{l}14.86 \\
6.86 \\
31.43 \\
19.43 \\
27.43 \\
\end{array}$ & $\begin{array}{l}45 \\
39 \\
130 \\
65 \\
71\end{array}$ & $\begin{array}{l}12.86 \\
11.14 \\
37.14 \\
18.57 \\
20.29 \\
\end{array}$ \\
\hline $\begin{array}{l}\text { Occupation } \\
\text { Business/small scale employees } \\
\text { Government employee } \\
\text { Private employee } \\
\text { Farmer/laborer } \\
\text { Unemployed }\end{array}$ & $\begin{array}{l}10 \\
42 \\
55 \\
31 \\
37 \\
\end{array}$ & $\begin{array}{l}5.71 \\
24.00 \\
31.43 \\
17.71 \\
21.14 \\
\end{array}$ & $\begin{array}{l}13 \\
20 \\
17 \\
63 \\
62 \\
\end{array}$ & $\begin{array}{l}7.43 \\
11.43 \\
9.71 \\
36.00 \\
35.43 \\
\end{array}$ & $\begin{array}{l}23 \\
62 \\
72 \\
94 \\
99 \\
\end{array}$ & $\begin{array}{l}6.57 \\
17.71 \\
20.57 \\
26.86 \\
28.29 \\
\end{array}$ \\
\hline $\begin{array}{l}\text { Annual income in rupees } \\
\quad<5,500 \\
5,501-10,000 \\
10,001-20,000 \\
20,001-30,000 \\
30,001-40,000 \\
>41,000\end{array}$ & $\begin{array}{l}12 \\
34 \\
40 \\
36 \\
29 \\
24 \\
\end{array}$ & $\begin{array}{l}6.86 \\
19.43 \\
22.86 \\
20.57 \\
16.57 \\
13.71 \\
\end{array}$ & $\begin{array}{l}0 \\
18 \\
10 \\
82 \\
39 \\
26\end{array}$ & $\begin{array}{l}0.00 \\
10.29 \\
5.71 \\
46.86 \\
22.29 \\
14.86 \\
\end{array}$ & $\begin{array}{l}12 \\
52 \\
50 \\
118 \\
68 \\
50\end{array}$ & $\begin{array}{l}3.43 \\
14.86 \\
14.29 \\
33.71 \\
19.43 \\
14.29\end{array}$ \\
\hline $\begin{array}{l}\text { Duration of illness } \\
\quad<1 \text { year } \\
1-3 \text { years } \\
4-5 \text { years } \\
6+\text { years }\end{array}$ & \begin{tabular}{|l|}
15 \\
69 \\
60 \\
31 \\
\end{tabular} & $\begin{array}{l}8.57 \\
39.43 \\
34.29 \\
17.71 \\
\end{array}$ & $\begin{array}{l}25 \\
33 \\
30 \\
87 \\
\end{array}$ & \begin{tabular}{|l|}
14.29 \\
18.86 \\
17.14 \\
49.71 \\
\end{tabular} & $\begin{array}{l}40 \\
102 \\
90 \\
118 \\
\end{array}$ & $\begin{array}{l}11.43 \\
29.14 \\
25.71 \\
33.71 \\
\end{array}$ \\
\hline $\begin{array}{l}\text { Sources of information } \\
\text { Radio } \\
\text { Television } \\
\text { News papers } \\
\text { Magazines and books } \\
\text { Medical professionals }\end{array}$ & $\begin{array}{l}20 \\
49 \\
21 \\
19 \\
66\end{array}$ & $\begin{array}{l}11.43 \\
28.00 \\
12.00 \\
10.86 \\
37.71\end{array}$ & $\begin{array}{l}27 \\
18 \\
6 \\
22 \\
102\end{array}$ & $\begin{array}{l}15.43 \\
10.29 \\
3.43 \\
12.57 \\
58.29\end{array}$ & $\begin{array}{l}47 \\
67 \\
27 \\
41 \\
168\end{array}$ & $\begin{array}{l}13.43 \\
19.14 \\
7.71 \\
11.71 \\
48.00\end{array}$ \\
\hline
\end{tabular}

$(22.86 \%)$ and control $=82(46.86 \%)]$ belong monthly income status was Rs. $10,001 /$ - to $20,000 /-$ per month. A majority of the respondents' [study $=69(39.43 \%)$ and control $=87(49.71 \%)]$ patients' duration of illness was 1-3 years. A majority of respondents [study $=66(37.71)$ and control $=102(58.29 \%)$ ] sought information from medical professionals. Both groups (study and control groups) were comparable in terms of their base-line characteristics (Table 1).

\section{Intervention effect}

The intervention effect was tested statistically by using inferential statistical tests, i.e. chi-square, $t$-test and ANOVA.

\section{Effectiveness of psycho-education on knowledge level regarding schizophrenia}

The effectiveness of psycho-education on knowledge regarding schizophrenia was evaluated among caregivers by comparing pre- and post-test scores, and the significance was tested by using the chi-square test (Table 2).

The results showed that at pre-test level, a majority [study = $161(92.0 \%)$ and control $=175(100 \%)]$ had an inadequate level of knowledge. At post-test-1, a majority of the study [142 (81.1\%)] group participants moved from the inadequate to adequate knowledge level, but control group participants remained at inadequate knowledge (85.1\%). These differences were significant at a 0.001 level $\left(\chi^{2}=291.84, d f=2\right)$. At post-test-2, the knowledge 
level of all the participants in the study group [ $n=175(100 \%)]$ moved to adequate level, while the knowledge level of a majority $[n=147(84.0 \%)]$ of control group participants remained at an inadequate level. The obtained chi-square value $\left(\chi^{2}=350.000, d f\right.$ $=2, p$-value $\left.=0.001^{* *}\right)$ is significant at the level of $p<0.01$.

The effectiveness of psycho-education on the knowledge level regarding schizophrenia among caregivers of patients with schizophrenia by comparing pre-test, post-test- 1 and post-test-2 scores and significance level was tested by using the $t$-test (Table 3 ).

The mean and SD at pre-test are (mean $=22.93, S D=17.03)$ (mean $=14.95, S D=13.75)$, respectively, in the study and control groups. The $t$-test value $(t=4.83)$ at post-test- 1 mean and $S D$ are $($ mean $=85.90, S D=9.51)($ mean $=30.01, S D=14.25)$, respectively, in the study and control group. The $t$-test value $(t=43.16)$ is significant at a $p<0.01$ level. At post-test- 2 , the mean and SD are $($ mean $=97.94, S D=4.41)($ mean $=38.40, S D$ $=13.62$ ), respectively, in the study and control group. The $t$-test value $(t=55.1)$ is significant at a $p<0.01$ level. The obtained $t$-test value at pre-test and post-test- 1 is $(t=-33.77)$ is significant at a level of $p<0.01$. The obtained $t$-test value at pre-test and post-test-2 is (-34.48) is significant at a level of $p<0.01$. The compared scores of pre-test, post-test-1, post-test 2 , mean, SD, $d f$, $t$-test values in the study and control groups prove the significance of psycho-educational intervention on imparting the knowledge level among study group caregiver compared with control group caregiver knowledge.

\section{Effectiveness of psycho-education on caregiver burden level}

Comparison of the level of caregiver burden before and after psycho-education at pre-test, post-test- 1 and post-test- 2 and significance was tested by using the chi-square test (Table 4).

\begin{tabular}{|c|c|c|c|c|c|c|c|}
\hline Levels of knowledge & $\begin{array}{l}\text { Study group } \\
n=175\end{array}$ & $\%$ & $\begin{array}{l}\text { Control group } \\
n=175\end{array}$ & $\%$ & Chi-square & $D f$ & $p$ \\
\hline \multicolumn{8}{|l|}{ Pre-test } \\
\hline Inadequate level & 161 & 92.0 & 175 & 100.0 & 14.59 & 1 & 0.001 \\
\hline Moderate level & 14 & 8.0 & 0 & 0.0 & & & \\
\hline Adequate level & 0 & 0.0 & 0 & 0.0 & & & \\
\hline \multicolumn{8}{|l|}{ Post-test-1 } \\
\hline Inadequate level & 0 & 0.0 & 149 & 85.1 & 291.84 & 2 & $0.001 * *$ \\
\hline Moderate level & 33 & 18.9 & 26 & 14.9 & & & \\
\hline Adequate level & 142 & 81.1 & 0 & 0.0 & & & \\
\hline \multicolumn{8}{|l|}{ Post-test-2 } \\
\hline Inadequate level & 0 & 0.0 & 147 & 84.0 & 350.00 & 2 & $0.001 * *$ \\
\hline Moderate level & 0 & 0.0 & 28 & 16.0 & & & \\
\hline Adequate level & 175 & 100.0 & 0 & 0.0 & & & \\
\hline Total & 175 & 100.0 & 175 & 100.0 & & & \\
\hline
\end{tabular}

\begin{tabular}{|l|l|l|l|l|l|}
\hline \multicolumn{6}{|l|}{ Table 3. Significance of findings on knowledge level on effectiveness of psycho-education, $\boldsymbol{n}=175$} \\
\hline Variable & Group & Mean & SD & $t$ & $p$ \\
\hline \multirow{3}{*}{ Pre-test } & study group & 22.93 & 17.03 & 4.83 & 0.001 \\
\cline { 2 - 7 } & control group & 14.95 & 13.75 & & \\
\hline Post-test-1 & study group & 85.90 & 9.51 & 43.16 & $0.001^{* *}$ \\
\cline { 2 - 7 } & control group & 30.01 & 14.25 & & \\
\hline \multirow{2}{*}{ Post-test-2 } & study group & 97.94 & 4.41 & 55.1 & $0.001^{* *}$ \\
\cline { 2 - 7 } & control group & 38.40 & 13.62 & & \\
\hline \multirow{2}{*}{ Pre-test - Post-test-1 } & study group & -62.97 & 16.91 & -33.77 & $0.001^{* *}$ \\
\cline { 2 - 7 } & control group & -15.06 & 8.13 & & \\
\hline \multirow{2}{*}{ Pre-test - Post-test-2 } & study group & -75.02 & 16.46 & -34.48 & $0.001^{* *}$ \\
\cline { 2 - 7 } & control group & -23.45 & 10.98 & & \\
\hline
\end{tabular}

$* * 0.01$.

\begin{tabular}{|c|c|c|c|c|c|c|c|}
\hline Levels of burden & $\begin{array}{l}\text { Study group } \\
n=175\end{array}$ & $\%$ & $\begin{array}{l}\text { Control group } \\
n=175\end{array}$ & $\%$ & Chi-square & $d f$ & $p$ \\
\hline \multicolumn{8}{|l|}{ Pre-test } \\
\hline Low level & 0 & 0.0 & 0 & 0.0 & 70.13 & 1 & 0.001 \\
\hline Average level & 67 & 38.3 & 4 & 2.3 & & & \\
\hline High level & 108 & 61.7 & 171 & 97.7 & & & \\
\hline \multicolumn{8}{|l|}{ Post-test-1 } \\
\hline Low level & 115 & 65.7 & 0 & 0.0 & 277.45 & 2 & $0.001^{* *}$ \\
\hline Average level & 60 & 34.3 & 26 & 14.9 & & & \\
\hline High level & 0 & 0.0 & 149 & 85.1 & & & \\
\hline
\end{tabular}




\begin{tabular}{|c|c|c|c|c|c|c|c|}
\hline Levels of burden & $\begin{array}{l}\text { Study group } \\
n=175\end{array}$ & $\%$ & $\begin{array}{l}\text { Control group } \\
n=175\end{array}$ & $\%$ & Chi-square & $d f$ & $p$ \\
\hline \multicolumn{8}{|l|}{ Post-test-2 } \\
\hline Low level & 165 & 94.3 & 0 & 0.0 & 314.77 & 2 & $0.001^{* *}$ \\
\hline Average level & 10 & 5.7 & 74 & 42.3 & & & \\
\hline High level & 0 & 0.0 & 101 & 57.7 & & & \\
\hline Total & 175 & 100.0 & 175 & 100.0 & & & \\
\hline
\end{tabular}

Table 5. Comparison of burden levels between study and control group subjects after psycho-education, $n=175$

\begin{tabular}{|l|l|l|l|l|l|}
\hline Variable & Group & Mean & SD & $t$ & $p$ \\
\hline \multirow{3}{*}{ Pre-test } & study group & 82.37 & 10.40 & -6.31 & 0.001 \\
\cline { 2 - 6 } & control group & 88.29 & 6.75 & & \\
\hline \multirow{2}{*}{ Post-test-1 } & study group & 49.13 & 8.28 & -39.48 & $0.001^{* *}$ \\
\cline { 2 - 6 } & control group & 82.73 & 7.63 & & \\
\hline \multirow{2}{*}{ Pre-test - Post-test-1 } & study group & 40.86 & 6.27 & -49.06 & $0.001^{* *}$ \\
\cline { 2 - 6 } & control group & 78.10 & 7.85 & & \\
\hline \multirow{2}{*}{ Pre-test- Post-test-2 } & study group & 33.24 & 4.97 & 65.48 & $0.001^{* *}$ \\
\cline { 2 - 6 } & control group & 5.55 & 2.57 & & \\
\cline { 2 - 6 } & ctudy group & 41.51 & 7.79 & 47.95 & $0.001^{* *}$ \\
\hline
\end{tabular}

\begin{tabular}{|c|c|c|c|c|c|}
\hline $\begin{array}{l}\text { Time of assess- } \\
\text { ment }\end{array}$ & $\begin{array}{l}\text { Study group } \\
\text { mean (SD) }\end{array}$ & $\begin{array}{l}\text { Control group } \\
\text { mean (SD) }\end{array}$ & Time effect & Group effect & Time $X$ group effect \\
\hline \multicolumn{6}{|c|}{ Caregiver burden } \\
\hline Pre-test & $49.42(6.23)$ & $52.97(4.05)$ & \multirow{3}{*}{$\begin{array}{l}F=4,786.7 \\
p<0.001 \\
\text { partial eta squared }=0.93\end{array}$} & \multirow{3}{*}{$\begin{array}{l}F=1,046.24 \\
p<0.001 \\
\text { partial eta squared }=0.75\end{array}$} & \multirow{3}{*}{$\begin{array}{l}F=1,940.01 \\
p<0.001 \\
\text { partial eta squared }=0.848\end{array}$} \\
\hline $\begin{array}{l}\text { Post-test-1 } \\
\left(1^{\text {st }} \text { month) }\right.\end{array}$ & $29.48(4.96)$ & $49.64(4.57)$ & & & \\
\hline $\begin{array}{l}\text { Post-test-2 } \\
\text { (3rd month) }\end{array}$ & $24.51(3.76)$ & $46.85(4.71)$ & & & \\
\hline \multicolumn{6}{|c|}{ Caregivers knowledge } \\
\hline Pre-test & $5.73(4.26)$ & $3.74(3.44)$ & \multirow{3}{*}{$\begin{array}{l}F=3,179.88 \\
p<0.001 \\
\text { partial eta squared }=0.90\end{array}$} & \multirow{3}{*}{$\begin{array}{l}F=1,306.06 \\
p<0.001 \\
\text { partial eta squared }=0.789\end{array}$} & \multirow{3}{*}{$\begin{array}{l}F=974.91 \\
p<0.001 \\
\text { partial eta squared }=0.737\end{array}$} \\
\hline $\begin{array}{l}\text { Post-test-1 } \\
\left.\text { (1 } 1^{\text {st }} \text { month }\right)\end{array}$ & $21.47(2.38)$ & $7.50(3.56)$ & & & \\
\hline $\begin{array}{l}\text { Post-test-1 } \\
\text { ( } 3^{\text {rd }} \text { month) }\end{array}$ & $24.48(1.10)$ & $9.6(3.40)$ & & & \\
\hline
\end{tabular}

The analyzed data revealed that at pre-test, a majority of study group $[n=108(61.7 \%)]$ and control group [ $n=$ $171(97.7 \%)]$ participants had a high level of burden. At posttest-1, the majority of the caregivers $n=115(65.7 \%)$ in the study group showed a reduction in burden level compared to control group subjects. The obtained chi-square value $\left(\chi^{2}=277.45, d f\right.$ $=2, p$-value $=0.001^{* *}$ ) was significant at a $p<0.01$ level. At post-test-2, the majority of subjects in the study group $[n=165$ (94.3\%)] showed lower levels of burden compared to control group subjects. The obtained chi-square value $\chi^{2}=314.77$, $d f=2, p$-value $\left.=0.001^{* *}\right)$ is significant at a $p<0.01$ level.

The effectiveness of psycho-education on caregivers, burden level among caregivers of patients with schizophrenia by comparing pre-test, post-test- 1 and post-test- 2 scores and significance level was tested by using the $t$-test (Table 5).

The results of the pre-test, mean and SD (mean $=82.37$ and SD $=10.40$ ) of the study group and (mean $=88.29$ and $\mathrm{SD}=6.75)$ of the control group and the obtained $t$-test value $(t=-6.31$, and $p=0.001)$ were compared with the post-test-1 values, mean and SD (mean $=49.13$ and $S D=8.28$ ) of the study group and (mean $=82.73$ and $S D=7.63$ ) of the control group, the obtained $t$-test value $(t=-39.48$, and $p=0.001)$ and also with post-test- 2 values, mean, $S D$ (mean $=40.86$ and $S D=6.27$ ) of the study group (mean $=78.10$ and $S D=7.85$ ) of the control group and the obtained $t$-test value $(t=-49.06)$ with significance at a level of $p<0.01$. At post-test-1, there was a statistically significant reduction in the burden level of study group subjects compared with control group subjects ( $t=-39.48, p=0.001$ ). At post-test-2, there was also a statistically significant reduction in the burden level among study group participants compared to control group participants $(t=47.95, p=0.001)$. The compared scores of pre-test, post-test- 1 , post-test- 2 , mean, SD, $d f$ and $t$-test values in the study and control groups proves the significance of psycho-educational intervention on reducing the burden level among study group caregivers compared with control group caregivers.

Repeated measures of ANOVA were conducted to verify the changes in the outcome variables from baseline to the threemonth follow-up (Table 6).

Repeated measures of ANOVA were conducted to verify changes in the outcome variables from baseline to the threemonth follow-up. There were significant psycho-education ef- 
fects in all of the outcome variables between the two groups. Compared with the control group, the study group showed a statistically significant decrease in caregiver burden $(F=1,940.01$, $p<0.001$, partial eta squared $=0.848$ ) and a statistically significant increases in caregiver knowledge $(F=974.91, p<0.001$, partial eta squared $=0.737$ ) over the three-month interval.

\section{Discussion}

Psycho-educational interventions may improve caregivers' knowledge of schizophrenia and have a positive impact on caregivers' burden level. Many studies thus far have shown that these interventions may improve patients' and caregivers' outcomes, but the quality of included randomized controlled trials is poor, and it is difficult to draw firm conclusions as to the effectiveness of such interventions on patients' and primary caregivers' outcomes, hence the present study intended to evaluate the efficacy of psycho-education on knowledge regarding schizophrenia and caregiver burden among caregivers of patients with schizophrenia. In order to achieve the objectives of the randomized controlled trial, a pre-test, post-test control group as an experimental approach was adapted. The participants were randomly assigned to either a study or control group via a computer-generated random sequence of numbers. The data was collected with the help of a structured interview schedule of a knowledge assessment questionnaire and a burden assessment schedule for 350 caregivers of patients with schizophrenia who were selected for the study. On the whole, subjects in study group showed a marked improvement in knowledge scores and a reduction in burden scores in two follow-ups compared to the control group which did not receive any psycho-education. This justifies the efficacy of psycho-education imparting knowledge regarding schizophrenia and burden reduction among caregivers of patients with schizophrenia. The findings of the present study are in accordance with earlier research studies [20-25], which have supported that psycho-educational interventions, along with routine treatment, are much more beneficial to the caregivers of patients with schizophrenia in order to take appropriate care of their relatives and in reducing their burden level.

The few studies that were conducted in India so far either mainly focused on the relationship between first-treatment contacts, supernatural beliefs in caregivers of patients with schizophrenia or religious and traditional modes of intervention, which are still widely practiced, especially in rural areas where mental health services are almost non exist. The present study attempted to investigate caregivers' knowledge on the aspect of the disease and management based on this. Psycho-education was provided and tested for effectiveness in the aspect of a gain in knowledge level regarding schizophrenia. An earlier study also supports the present study results that psycho-educational intervention is effective in improving relatives' knowledge about schizophrenia and reducing re-hospitalization. This is effective in increasing their knowledge about schizophrenia, as well as reducing their burden regarding the care of their relatives. The study results also note that the majority of the caregivers showed a high level of burden, both in the study and control groups, before implementing psycho-education to the study group. Finally, the study results identified the need of psycho-education for caregivers to reduce their burden level. The study highlighted the importance of setting targets for improving the functionality of patients in the design and implementation of rehabilitation and support programs to the caregivers of patients with schizophrenia. While supporting earlier research recommendations, the present study has attempted to prove the importance of psycho-educational intervention as one type of support program for caregivers of patients with schizophrenia. In addition to this, there were limited studies focusing on the Indian population. Caregiver education, which proved effective in other countries, was recommended for application within the Indian population. Therefore, it was important to test the efficacy of psycho-education in improving the knowledge about this illness and the ability to reduce the level of burden among caregivers of patients with schizophrenia. The findings of the present study have proved the effectiveness of psycho-education on caregivers of patients with schizophrenia. This study has provided strong evidence that psychiatric nurses can effectively implement psycho-education to caregivers and also shows the importance of a nurse's role as a psycho-educator in the mental health settings.

\section{Limitations of the study}

The study was limited to caregivers of patients with schizophrenia, so, the study results have limitation in generalization to other types of the psychiatric conditions, and the long-term effects could also not be established due to the time constraint.

\section{Conclusions}

Psycho-education interventions implemented by psychiatric nurses have statistically and significantly increased the knowledge level of caregivers regarding schizophrenia and also reduced the caregiver's burden level among the study group caregivers compared to control group caregivers, who received routine care of the hospital. Based on the findings of the study, structured psycho-educational interventions should be considered as an integral component of care to patients with schizophrenia. The study recommends that mental health settings should compulsorily adapt psycho-education units that specifically function to impart knowledge on mental illnesses to the relatives and patients who come for treatment. Authorities can make available information brochures about mental illnesses to the public, so as to help them in coping better with these illnesses.

Source of funding: This work was funded from the authors' own resources.

Conflicts of interest: The authors declare no conflicts of interest.

\section{References}

1. Global, regional, and national incidence, prevalence, and years lived with disability for 328 diseases and injuries for 195 countries, 1990-2016: a systematic analysis for the Global Burden of Disease Study 2016. Lancet 2017; 390(10100): 1211-1259.

2. Saha S, Chant D, Welham J, et al. A systematic review of the prevalence of schizophrenia. PLoS Med 2005; 2(5): e141.

3. Moreno-Küstner B, Martín C, Pastor L. Prevalence of psychotic disorders and its association with methodological issues. A systematic review and meta-analyses. PLOS ONE 2018; 13(4): e0195687.

4. Awad AG, Voruganti LN. The burden of schizophrenia on caregivers: a review. Pharmacoeconomics 2008; 26: 149-162.

5. Schene AH, van Wijngaarden B, Koeter MW. Family caregiving in schizophrenia: domains and distress. Schizophr Bull 1998; 24: 609-618.

6. Pai S, Kapur RL. The burden on the family of a psychiatric patient: development of an interview schedule. Br J Psychiatry 1981; 138: 332-335.

7. Murthy R.S. National mental health survey of India 2015-2016. Indian J Psychiatry 2017; 59(1): 21-26. 
8. World Health Organization. WHO Mental health Gap Action Programme. Available from: hht:///www.who.int/mental_health/mhgap/ en/.

9. Pareddi V, Blrudu R, Thimmaiah R, et al. Mental health literacy among caregivers of persons with mental illness: a descriptive survey. J Neurosci Rural Pract 2015; 6(3): 355-360.

10. Padmavati R. Rajkumar S, Kumar N. Prevalence of schizophrenia in an urban community in Madras. Indian J Psychiatry 1987; 30: 233-239.

11. Yazici E, Karabulut Ü, Yildiz M, et al. Burden on caregivers of patients with schizophrenia and related factors. Noro Psikiyatr Ars 2016; 53(3): 96-101.

12. Hsiao CY, Tsai YF. Factors of caregivers burden and family functioning among Taiwanese family caregivers living with schizophrenia. J Clin Nurse 2015; 24(11-12): 1546-1556.

13. Chien WT, Chan SW, Morrissey J. The perceived burden among Chinese family, caregivers of people with schizophrenia. J Clin Nurse 2007; 16(6): 1151-1161.

14. Cassidy E, Hill S, O'Callaghan E. Efficacy of psycho-educational intervention in improving relatives knowledge about schizophrenia and reducing rehospitalization. Eur Psychiatry 2001; 16(8): 446-450.

15. Paranthaman V, Satham K, Lim Jl, et al. Effective implementation of a structured psycho-education programme among caregivers of patients with schizophrenia in the community. Asian J Psychiatr 2010; 3(4): 206-212.

16. Sunanda GT. Study Establishes connection between inadequate knowledge and unfavorable Attitude of family members of schizophrenic patients. Nightingale Nursing Times 2008; 4(2): 65-66.

17. Thara R, Padmavati R, Kumar S, et al. Burden assessment schedule. Indian J Psychiatry 1998; 40(1): 21-29.

18. Verghese M, Auish S, Uday Kumar GS. Family intervention and support in schizophrenia. Version 2. Bangalore: National Institute Of Mental Health And Neurosciences; 2002.

19. Anderson C, Reiss D, Hogarty G. Schizophrenia and the family; a Practioner's guide in psycho-education and management. New York: Guilford Press; 1986.

20. Nasr T, Kausar RS. Psycho-education and the family burden in schizophrenia, a randomized controlled trail. Ann Gen Psychiatry 2009; 8: 17, doi: 10.1186/1744-859X-8-17.

21. Fiorillo $A$, Bassiom, de Giroloma $G$, et al. The impact of a psycho-educational intervention on family members views about schizophrenia; results from the Italian multi centre. Int J Soc Psychiatry 2010; 57(6): 596-603.

22. Chien WT. Effectiveness of psycho-education and mutual support group program for family caregivers of Chinese people with schizophrenia. Open Nurs J 2008; 2: 28-39.

23. Warakul P, Thavichachart N, Lueboonthavatchia P. Effects of psycho-educational programs. J Med Assoc Thai 2007; 90(6): 1199-1204.

24. Navidian A, Kermansaravi F, Rigi SN. The effectiveness of a group psycho-educations program on family caregiver burden of patients with mental disorders. BMC Res Notes 2012; 5: 399, doi: 10.1186/1756-0500-5-399.

25. Gutiérrez-Maldonado J, Caqueo-Urizar A, Ferrer-Garica M. Effects of a psycho educational intervention program. BMC Fam Pract 2011; 12(1): 101.

Tables: 6

Figures: 1

References: 25

Received: 20.09.2018

Reviewed: 25.09.2018

Accepted: 13.12 .2018

Address for correspondence:

Sunanda Govinder Thimmajja, MSc(N), PhD, RN, Assoc. Prof.

Department of Psychiatric Nursing

Dharwad Institute of Mental Health and Neurosciences

Belagavi Road, Dharwad 580008

India

Tel.: 9611814496

E-mail: amogh_aniketh@yahoo.com 